\title{
LOS FANTASMAS DE CLIO. A PROPOSITO DE FRANQUISMO Y FASCISMO EN LA PERSPECTIVA DE LA HISTORIA COMPARADA ${ }^{1}$
}

\author{
Alfonso Botti \\ Universidad de Urbino
}

1. Pendiente desde hace algunas décadas, el problema de la comparación entre el régimen de Franco y el de Mussolini queda aún lejos de estar resuelto. Es más. Al historiador que quiere acercarse al tema le suele pasar lo que se cuenta de los viejos viajeros en Escocia. Igual que éstos, cruzado el bosque, llegaban exhaustos al castillo donde se encontraban con la amarga sorpresa de sus habitantes nocturnos, así el historiador que haya conseguido destrejarse en la foresta de los enfogues y de las interpretaciones, llegado por fin a la meta, tiene además que enfrentarse con unos fantasmas, cuya naturaleza resultará clara más adelante.

Como se sabe, los primeros intentos de comparación surgen en los ambientes de la Tercera Internacional ya en los años veinte y la aportación del análisis marxista del fenomeno fascista tendrá mucha influencia en los estudios sucesivos. Conocido es además que es en la segunda posguerra cuando la historiograî́a elabora una noción de fascismo como categoría incluyente de experiencias históricas diferentes, mientras otros discuten la amplitud de esta inclusión ${ }^{2}$. Merece destacar, entre los primeros intentos de elaborar un modelo de fascismo capaz de englobar a algunos de los "fascismos reales" el de Ernst Nolte ${ }^{3}$.

Después de Hannah Arendt ${ }^{4}$ la categoría de totalitarismo ha sido empleada por muchos científicos sociales en lugar de la de fascismo. Casi nunca en su versión original, que limitaba el modelo totalitario a la Alemania de Hitler y a la Unión Soviética en la edad estaliniana, sino en la versión ampliada de Carl J. Friedrich y Zbigniew K. Brzezinski ${ }^{5}$. Mientras que lo que ha significado para el estudio del franquismo el modelo de régimen autoritario elaborado por Juan J. Linz, no hace falta decir nada, ni tan siquiera en nota.

La categoría de totalitarismo está hoy en crisis. Se la critica desde la izquierda, por parte de quienes nunca han aceptado las abstracciones desde países e historias

\footnotetext{
${ }^{1}$ Dado el carácter de borrador y el tono coloquial de esta intervención, las citas bibliográficas han sido reducidas al mínimo indispensable. Lamento además no haber tenido la oportunidad de averiguar todas las eventuales ediciones españolas de los libros que, por esto, cito en su versión original y/o en la italiana.

${ }^{2}$ Enzo Collotti, Fascismo, fascismi, Firenze, Sansoni, 1989, también por su reseña de la historiografía al respecto.

${ }^{3}$ E. Nolte, Der Faschismus in seiner Epoche, München, R. Piper, 1963.

${ }^{4}$ H. Arendt. The Origins of Totalitarism, New York, Harcourt Brace, 1951.

${ }^{5}$ C. J. Friedrich (ed), Totalitarism, Cambridge, Harvard University Press, 1954; C. J. Friedrich, Z.K. Brzezinski, Totalitarim, Dictatorship and Autocracy, Cambridge, Harvard University Press, 1956.
} 
tan diferentes que están en raíz 6 . Se la critica desde la derecha, por parte de Nolte que ve en el bolchevismo el antecedente causal del nacionalsocialismo ${ }^{7}$. Pero más dura aún resulta la crítica de los hechos: baste pensar en como la transición real hacia el post-comunismo en la Unión Soviética encaja muy poco con las características que se han atribuido a este régimen dentro del "tipo ideal" de totalitarismo. Discrepancia que nos ayuda a rechazar las generalizaciones superficiales y a superar la confusión entre las aspiraciones totalitarias (que se refieren al pensamiento político y las ideologías) con las concretas experiencias históricas y los regímenes reales ${ }^{8}$.

Por otra parte, también el debate sobre los problemas de estatuto científico, de enfoque y metodológicos, relacionados con la comparación histórica, se han desarrollado mucho desde cuando Henri Pirenne y Marc Bloch plantearon esta posibilidad y necesidad en los años veinte ${ }^{9}$.

La comparación histórica parece constituir un concreto espacio epistemológico, relacionado por un lado con las teorías generales de la historia, por otro con las ciencias sociales $^{10}$. Espacio, entonces, no vacio, sino poblado por varias disciplinas, ideologías, taxonomías, modelos interpretativos, filosofías de la historia, e incluso, por la subjetividad y sensibilidad de los distintos historiadores, hasta el punto que podría mejor calificarse de campo de batalla, dentro del cual se mezclan disciplinas diferentes, mientras a su alrededor disputan las distintas corporaciones de científicos sociales que levantan un polvo que impide averiguar donde acaban los intereses académicos-corporativos y donde empiezan los estatutos epistemológicos.

Parece cierto, de todas formas, que a la definición de este espacio han contribuido dos fenómenos. Por un lado la crisis de la idea del siglo XVIII-XIX de una historia universal, unilineal, concebida como desarrollo ascendiente y progresivo. Por otro, el nuevo encuentro (el primero ya se había registrado con la influencia de Emile Durkheim sobre Marc Bloch), allá por los años sesenta, con la sociología postparsoniana que estrena una distinta aproximación al estudio de los procesos de modernización, y que individúa dos vías hacia la modernidad: la liberal demócrata y la relacionada con los regimenes autoritarios que modernizan (o lo intentan) "desde

\footnotetext{
${ }^{6} \mathrm{Y}$, por supuesto, no solo desde la izquierda, como demuestran, entre otras, las páginas de R. Aron, Démocratie et totalitarisme, Paris, 1965 (ed. it. Teoria dei regimi politici, Milano, 1973, pp. 238 ss.).

${ }^{7}$ E. Nolte, Nazionalsocialismo e bolscevismo. La guerra civile europea, 1917-1945, Firenze, Sansoni. 1988.

${ }^{8}$ S. Avineri, "Per una tipologia del totalitarismo", en Lettera Internazionale, VIII (1992), n. 32, pp. 7-9.

${ }^{9}$ H. Pirenne, "De la méthode comparative en histoire", en G. Des Marez y F.L. Ganshof (eds), Compte rendu du V Congrès international des Sciences historiques, Bruxelles, 1923, pp. 19-32; M. Bloch, "Pour une histoire comparé des societés européennes", en Revue de Synthèse historique, 1928, pp.15- 50. Entre los últimos aportes en el plano teórico, destacan: C.S. Mainer, "La storia comparata", en G. De Luna, P. Ortoleva, M. Revelli, N. Tranfaglia (eds), Introduzione alla storia contemporanea, Firenze, La Nuova Italia, 1984, pp. 335-351; P. Rossi (ed), La storia comparata. Approcci e prospettive, Milano, Il Saggiatore, 1990.

${ }^{10} \mathrm{P}$. Rossi, "Introduzione", en La storia comparata, cit., pp. IX-XXV.
} 
arriba"ll.

Así que la comparación se presenta hoy como el lugar privilegiado del enfrentamiento entre la historiografía y la sociología ${ }^{12}$, hasta el punto que resulta dificil distinguir entre historia comparada y sociología histórica que de la comparación entre los procesos de modernización ha hecho su propio programa ${ }^{13}$, y para aproximarse a la cual el lector español puede aprovechar de las muy útiles reflexiones de Santos Juliá ${ }^{14}$.

Queda en cualquier caso claro -difícil sería admitir lo contrario- que ya no puede reconocerse validez científica a cualquier intento comparativo fuera de un marco metodológico y teóricamente formulado. Marco para aproximarse al cual resultan útiles las categorías de objeto de la comparación y de propriedades comparadas con relación a un determinado objeto ${ }^{15}$, en el sentido que a los dos términos da Luciano Cafagna, según el cual por objeto, habría que entender "una entera agregación humana, concreta e histórica", de manera que, "por ejemplo, los procesos de modernización serían propriedades comparables con relación a diferentes objetos territoriales o político-territoriales ${ }^{116}$.

2. Por contra, una rápida mirada al panorama que nos ofrecen las investigaciones comparativas en el ámbito internacional y europeo ${ }^{17}$, nos permite destacar, con las

\footnotetext{
${ }^{11}$ Idem, p. XVI. El lector español puede ahora ver: T. Camero Arbat (ed), Modernización, desarrollo político y cambio social, Madrid, Alianza, 1992.

${ }^{12}$ Para orientarse en la que ya puede enmarcarse entre la nuevas vexata quaestio, cfr.: Cfr. L. Gallino, "Storia e scienze sociali", en Introduzione alla storia contemporanea, cit., pp. 281-306; M. Revelli, "Storia e scienze sociali: un approccio storico", idem, pp.307-334; J. Aróstegui, "Sociología e historiografía en el análisis del cambio social reciente", en Historia Contemporánea, 1990, n. 4, pp. 145-172. Un replantamiento de las relaciones entre historia y ciencias sociales ha sido auspiciado por el editorial "Histoire et sciences sociales. Un toumant critique?", en Annales E.S.C., XLIII (1988), pp. 291-293. Cierto malestar difundido entre los historiadores españoles se puede apreciar en la recopilación Debates por una historia viva, Bilbao, Universidad de Deusto, 1990.
}

${ }^{13}$ P. Rossi, "Introduzione", cit., p. XVI.

${ }^{14}$ S. Juliá, Historia sociallsociología histórica, Madrid, Siglo XXI, 1989.

${ }^{15}$ A. Marradi, "Forme e scopi della comparazione", Introducción a N.J. Smelser, La comparazione nelle scienze sociali, Bologna, Il Mulino, 1982; A. Marradi, "Natura, forme e scopi della comparazione. Un bilancio", in D. Fisichella (ed), Metodo scientifico e ricerca politica, Roma, NIS, 1985, pp. 293-321.

${ }^{16}$ L. Cafagna, "Comparazione e modemizzazione nella storiografia", en P. Rossi (ed), La storia comparata, cit. p. 383. Una postura menos radical -por así decirlo- con respecto a la "totalidad" del objeto a considerar, es la de Alessandro Cavalli según el cual las propriedades se refieren tendencialmente a estructuras o a procesos, mientras que los objetos que indica son los Estados. Así que la comparación no sería entre los Estados (incomparables por su unicidad), sino entre las propriedades; mejor dicho: entre "los estados relativos a una o más propriedades". A. Cavalli, "Sul rapporto tra scienze sociali e storia comparata", en P. Rossi (ed), La storia comparata, cit., p. 411.

${ }^{17} \mathrm{Al}$ margen del mundo anglosajón, que ha producido al respecto las obras más significativas y que está marcando una especie de hegemonía con la revista Comparative Studies in Society and History, parece ser Alemania el país donde la historia comparada, a través de las investigaciones de Theodoro Schieder, Gerard A. Ritter, la recuperación de Otto Hintze y la neu Sozialgeschichte con los trabajos de Hans-Ulrich 
excepciones que siempre hay ${ }^{18}$ y a pesar de los muchos ruidos en el trasfondo, el escaso interés por parte de las historiografías española e italiana hacia la comparación y, sobre todo, la falta casi absoluta de reflexión teórica y metodológica en los pocos casos en los cuales los intentos de comparación se han llevado a cabo. Un defecto -es preciso añadir- que la historiografía hispanística, en su gran mayoría, también comparte.

Las tres vertientes (la italiana, la hispanista y la española) desde las cuales se mira hacia España están fuertemente caracterizadas. Pero no se trata de una diferenciación nacional (y, por supuesto, mucho menos nacionalista). Cada vertiente tiene algo cultural e historiográficamente peculiar, que a veces influye y en ocasiones determina el proceso a través del cual se genera en la mente del historiador el "problema histórico" en la base del cual Cafagna ve "el mundo de las fermentaciones analógicas"19.

Aún sin propósito comparativo puede surgir en el estudio de un objeto $\mathrm{Y}$, la analogía con un objeto $X$, que se ha estudiado previamente, así que se reconoce en $\mathrm{Y}$ algo de $\mathrm{X}$. Este procedimiento afecta en particular al que se dedica (o que se dedica también), a la historia de un país que no es el suyo. Puesto que nadie nace hispanista -para hacer un ejemplo cercano- se supone que la formación del que llega a ser un hispanista empieza sobre la historia de su propio país. Y de todas formas es atípico que un proceso de formación excluya justamente la historia del país donde se ha nacido, cursado la carrera y hecho curriculum. Es esta historia que constituye el objeto X, en relación al cual, puede reconocerse (o no) en el objeto $\mathrm{Y}$ algo de $\mathrm{X}$. $Y$ es generalmente a partir de esta historia que surge el proceso analógico, sea como fuera, implícito, inconsciente o muy razonado.

Así que, para sacar algunos ejemplos de un hispanista entre los más conocidos,

Wehler, Hans-Jürgen Puhle y Jürgen Kocka, marca las pautas. Véanse al respecto: G. Comi, "La comparazione nella nuova storia sociale tedesca", en P. Rossi (ed), La storia comparata, cit., pp. 274-289; J. Kocka, "I nuovi interrogativi della storiografia tedesca", en Passato e Presente, XI (1993), n. 28, pp. 42-51. Sobre el estado de las investigaciones en Francia e Inglaterra, véanse: H.G. Haupt, "La Francia: una tradizione persa" y G. Crossick, " $E$ che cosa si può sapere dell'Ingliterra? La storia comparata in Gran Bretagna", en Passato e Presente, cit., pp. 20-41.

${ }^{18}$ Dejando al margen las que no son verdaderas comparaciones, sino recopilaciones donde cada uno presenta lo suyo y la comparación, por así decirlo, corresponde al inocente y despistado lector, el mayor número de publicaciones se encuentran en el campo de la historia económica. Entre ellas merece destacar L. Garruccio, L'industrializzazione tra nazionalismo e rivoluzione, Bologna, Il Mulino, 1969, pp. 297-302; R. Vaccaro, "Industrialization in Spain and Italy (1860-1914)", en Journal of European Economic History, 1981, n. 3, pp. 709- 751, y las más recientes A. Grohmann (ed), Due storiografie economiche a confronto: Italia e Spagna dagli anni ' 60 agli anni '80, Milano, Università Bocconi-Giuffrè, 1991; L. Prados de la Escosura y V. Zamagni (eds), El desarrollo económico en la Europa del Sur: España e Italia en perspectiva histórica, Madrid, Alianza, 1992. Fuera del ámbito económico, véase G. Ranzato, "La forja de la soberanía nacional: las elecciones en los sistemas liberales italiano y español", in Ayer, 1991, n.3, pp. 115-138.

${ }^{19}$ L. Cafagna, "Storia comparata e contesti disciplinari", cit., p. 382. Tambén véase, del mismo autor, el anterior artículo sobre "La comparazione e la storia contemporánea", en Meridiana, 1989, n. 6, pp.15-28. Mientras, sobre la anología en el pensamiento historiográfico, siguen siendo sugerentes las páginas de L. Canfora, Analogia e storia, Milano, Il Saggiatore, 1982, pp. 11-36. 
cuando Raymond Carr aborda el problema cubano a finales del siglo XIX español (papel de los EE.UU. aparte) reconoce algo de las relaciones entre Gran Bretaña e Irlanda y establece una relación entre Maura y Gladstone por sus actitudes políticas frente a las dos islas. Escribe también que contra el liberalismo ilustrado Romero Robledo tuvo el papel del Chamberlain español (mientras un historiador italiano ve en el ministro Nicotera, "el Romero Robledo italiano"20. Establece además varios paralelismos: entre el Gales occidental de los años treinta del siglo XIX y algunas regiones españolas alrededor de 1890; entre Giorgio III y Alfonso XIII; entre el Partido Republicano Reformista de 1912 y la izquierda liberal inglesa de 1906. Considera, en fin, que Gil Robles habría podido llegar a ser un Parnell español ${ }^{21}$.

Existe además otra circunstancia. Concretamente aquélla en la cual en la raíz del proceso de generación en la mente del historiador del "problema histórico" están, no otras historias, sino otras historiografías y modelos interpretativos. Y esto bajo un doble aspecto: 1) en el sentido de que el estudio del objeto $Y$ sugiere el empleo de modelos interpretativos elaborados en el estudio del objeto $X ; 2$ ) o en el sentido de que es el mismo objeto $\mathrm{Y}$ que se construye como objeto a partir del antecedente historiográfico de la construcción de X como objeto. Se puede pensar en la influencia que ha tenido el modelo francés de revolución burguesa en el estudio del siglo XIX español ${ }^{22} \mathrm{o}$ en lo sugerente que resultaría comparar, en el plano de la historia de la historiografía, la peculiar via alemana (Sonderweg) con los paradigmas proto-historiográficos de la Historia general de España de Modesto Lafuente y con todo lo que está relacionado con la leyenda negra ${ }^{23}$.

Pero, sin más, ya es hora de volver a las tres vertientes para considerar de cada una algunas de las posturas más representativas.

3.1. En Italia han sido algunos de los historiadores especialistas en el fascismo, los que han abordado de alguna forma el tema de la comparación entre los dos regímenes. Enzo Collotti, estudioso de la Alemania hitleriana y del fenómeno nazi-fascista en general, teniendo dudas sobre el valor heurístico de la categoría de totalitarismo, acepta y contribuye a definir un concepto general de fascismo. Entre

${ }^{20}$ G. Ranzato, "La forja de la soberanía nacional...", cit., p. 130.

${ }^{21}$ Me refiero al segundo volumen de la edición italiana: R. Carr, Storia della Spagna, 1808-1939, Firenze, La Nuova Italia, 1978, y concretamente a las pp. 476-477, 479, 480, 544, 601, 681 y 797.

${ }^{22}$ Véase J.S. Pérez Garzón, "La Revolución burguesa en España: los inicios de un debate científico, 1966-1979", en M. Tuñón de Lara (ed), Historiografía española contemporánea, Madrid, Siglo XXI, 1980, pp. 92-138.

${ }^{23} \mathrm{Mi}$ investigación sobre el modemismo religioso en España (La Spagna e la crisi modernista, Brescia, Morcelliana, 1987), no habría sido posible sin el anterior estudio e interés hacia el fenómeno modernista europeo e italiano en particular, así como mi trabajo sobre el nacionalcatolicismo (Cielo y dinero. El nacionalcatolicismo en España, 1881- 1975, Madrid, Alianza, 1992) tiene llaves interpretativas elaboradas (o aplicadas) a Italia por la historiografía italiana. El reciente intento de Feliciano Montero de leer la historia del catolicismo contemporáneo español en el marco de la categoría de "movimiento católico" va en la misma dirección (El movimiento católico en España, Madrid, Eudema, 1993). Pero, por supuesto, los ejemplos podrían ser miles. 
cuyas variantes pone un "área de fascismo católico" dentro de la cual coloca la experiencia franquista ${ }^{24}$.

Una postura que comparte Luciano Casali, que además tiene competencia como hispanista ${ }^{25}$. También otro historiador del fascismo italiano, Nicola Tranfaglia, opina que el franquismo, a pesar de importantes diferencias, se inscribe, por lo menos la primera década, entre las variedades de fascismo existentes en Europa ${ }^{26}$.

Un caso aparte y discrepante es el de Renzo De Felice cuya conocida tendencia es la de considerar al fascismo italiano como fenómeno muy diferente del nazismo y como algo peculiar que empieza y acaba en el contexto italiano. También conocida es su respuesta a la pregunta sobre el franquismo que, según él, "indudablemente" no es un régimen fascista (en 1975) y según el cual "habría que discutir si nunca lo ha sido. Más probablemente es un clásico régimen autoritario con algunos injertos modernos, pero nada más que esto"27.

A pesar de que esta postura parece no aconsejar la comparación con el franquismo, las claves interpretativas empleadas por De Felice parecen aplicables al contexto español. El tema del consenso, por ejemplo, ha estado en el centro de la discusión en el Seminari barcelonés de mayo de $1987^{28}$, y -aún si muy de paso- otra aproximación ha sido intentada por Gabriele Ranzato ${ }^{29}$.

3.2. Entre los hispanistas, quien antes y mejor se ha caracterizado por el estudio comparativo de los regímenes italiano y español, es indudablemente el estadounidense Stanley G. Payne. Sus aportaciones al tema del fascismo como generalidad ${ }^{30}$, a la evolución de las corrientes nacionalistas en los dos países ${ }^{31}$ y a la historia del franquismo quedan como punto de referencia fundamental ${ }^{32}$. El problema es que quedan, que no se mueven, en el sentido de que Payne lleva mucho tiempo proponiendo una interpretación comparativa que, por lo que se refiere a la historia italiana,

${ }^{24}$ E. Collotti, "Cinque forme di fascismo europeo. Austria, Germania, Italia, Spagna, Portogallo", en L. Casali (ed), Per una definizione della dittatura franquista, Milano, Angeli, 1990, p. 47.

${ }^{25}$ L. Casali, "Il fascismo di tipo spagnolo", en Per una definizione della dittatura franchista, cit., pp. 7-37.

${ }^{26}$ N. Tranfaglia, "Italia e Spagna: due regimi autoritari a confronto", en Labirinto italiano, Firenze, La Nuova Italia, 1989, pp. 21-39.

${ }^{27}$ R. De Felice, Intervista sul fascismo, a cura di M.L. Ledeen, Bari, Laterza, 1975, pp. 60-61.

${ }^{28}$ VV.AA., Franquisme. Sobre resistència $i$ consens a Catalunya (1938-1959), Barcelona, Centre de Treball i Documentació/Editorial Crítica, 1990.

${ }^{29}$ G. Ranzato, "All'origine della base di massa del regime franchista", en Per una definizione della dittatura franchista, cit., p. 155.

${ }^{30}$ S.G. Payne, The Concept of Fascism en E.U. Larsen, B. Hagtvet y J.P. Myklebust (eds), Who were the Fascists. Social Roots of European Fascism, Bergen-Oslo-Tromsö, Universitetsforlaget, 1980; Fascism. Comparison and definitions, The University of Winsconsin Press, 1980 (tr. esp.: El fascismo: comparación y definición, Madrid, Alianza, 1982). Pero véase también: Falange, París, Ruedo Ibérico, 1965.

${ }^{31}$ S.G. Payne, "La derecha en Italia y España (1910-1943)", en Política y sociedad en la España del siglo XX, Madrid, Akal, 1978, pp. 185-203.

${ }^{32}$ S.G. Payne, El régimen de Franco, 1936-1975, Madrid, Alianza, 1987. 
se ha parado en la producción historiográfica sobre el nacionalismo de los sesenta ${ }^{33}$, y que, con relación a los procesos de modernización, sigue en la óptica que considera opuestas tradición y modernidad, prejuicio que le impide valorar adecuadamente el papel del factor religioso en la historia española. Así que las páginas conclusivas de su historia del régimen franquista dejan como contradición no resuelta la caracterización católica del régimen (un catolicismo tradicional, arcaizante, antimoderno, etc.) con la de un Franco "modemizador económico consciente y decidido"34 y con la modernización "siempre un objetivo prioritario del régimen"35.

A pesar de esto, Payne, ha criticado la tendencia a exagerar diferencias acusadas entre los regímenes de Franco y Mussolini, pues "si se estableciera una tipología comparativa general, habría que reconocer mayor importancia a las similitudes" ${ }^{36}$.

3.3. Por lo menos desde un punto de vista los historiadores españoles han jugado con cierta ventaja. Puesto que el franquismo ha tenido, por algún tiempo indudablemente, como paradigma al fascismo italiano, ellos no tenían otro remedio que enterarse de este modelo, y para llevar a cabo esta tarea han encontrado un número considerable de investigaciones y de trabajos de síntesis. No extraña entonces que los que mejor controlan el tema en las dos vertientes se encuentren entre los contemporaneístas españoles. Entre ellos Antonio Elorza y Javier Tusell. El primero a partir de un enfoque más preocupado de los aspectos ideológicos y con especial atención al fascismo español en relación con el italiano ${ }^{37}$. El segundo con una visión más de conjunto y según los clásicos cánones de la historia política en su La dictadura de Franco.

Sobre este último merece la pena detenerse porque, al margen de las críticas que se le pueden hacer y de las discrepancias que se pueden registrar, hay que reconocer que constituye un punto de referencia del cual no se puede prescindir, ésto por algunas razones que merece la pena destacar de antemano. Concretamente: por la enunciación de la diferencia existente entre la perspectiva histórica y la de otras ciencias sociales; porque mientras reconoce su deuda con Linz, indica la estaticidad de su modelo interpretativo; en tercer lugar porque elige, entre los posibles, los aspectos más importantes para llevar a cabo la comparación; y, en fin, porque tiene muy clara la dificultad de carácter cronológico que supone esta comparación.

\footnotetext{
${ }^{33}$ Es decir que no tiene en consideración la renovación de los estudios sobre el nacionalismo italiano que han significado los trabajos de Silvio Lanaro a partir del artículo "Nazionalismo e ideologia del blocco corporativo-protezionista in Italia", en Ideologie, 1967, n. 2. Y sobre todo, con los libros Nazione e lavoro. Saggio sulla cultura borghese in Italia, 1870-1925, Venezia, Marsilio, 1979 y L'Italia nuova. Identità $e$ sviluppo, 1861-1988, Torino, Einaudi, 1988.

${ }^{34}$ S. G. Payne, El régimen de Franco, 1936-1975, cit., p. 654.

${ }^{35}$ Idem, p. 667. Se aborda de paso esta cuestión también en A. Botti, "Il nazionalismo spagnolo nella ricerca e nel dibattito storiografico", en Italia contemporanea, 1993, n. 191.

${ }^{36}$ S.G. Payne, "La derecha en Italia y España (1910- 1943)", cit. p. 200.

${ }^{37}$ A. Elorza, "Le radici ideologiche del franchismo", en Per una definizione della dittatura franchista, cit., pp. 57-77; "Le vie del fascismo (1931-1936)", en G. Di Febo, C. Natoli (ed), Spagna anni Trenta. Società, cultura, istituzioni, Milano, Angeli, 1993, pp. 141-165.
} 
Por lo que se refiere al ascenso al poder, Tusell subraya justamente el camino por etapas de Mussolini hacia el verdadero régimen, frente a una ruptura con el pasado más clara en el caso español. Según su interpretación existiría una coherencia interna en la evolución del fascismo hacia el totalitarismo que no hay en el franquismo ${ }^{38}$, cuya evolución y adaptaciones camaleónicas considera determinadas por las circunstancias. Habría al respecto que valorar las diferencias entre el programa fascista de 1919 y su realización (es decir las diferencias entre movimiento y régimen), para comprobar si efectivamente se trata de un desarrollo lineal o mediatizado por los compromisos que Mussolini tuvo que hacer con las fuerzas más tradicionales y conservadoras de la sociedad italiana. Pero, ino es un importante cambio de trayectoria, causado por circunstancias externas (la influencia alemana y el pacto con Hitler) lo que se produce en la actitud frente a los judíos y en la política racial del régimen desde 1938? Además habría que considerar que si el fascismo italiano tiene cierta coherecia en su desarrollo no es porque en él no influyen las circunstancias externas, sino justamente por lo contrario. Es decir que son justamente las circunstancias externas (prudencia y miedo de las democracias occidentales, aislamiento de la Unión Sovietica y de los EE.UU..., etc.) las que permiten a Mussolini cierta trayectoria. Circunstancias de las cuales no goza Franco que tiene que sobrevivir en la Europa de la post-guerra, muy diferente del panorama internacional que Mussolini había tenido en frente. Siempre a este respecto, Tusell recuerda que "De Felice ha llegado a afirmar que si Mussolini no hubiera entrado en la guerra mundial, su régimen podría haber evolucionado en un sentido semejante a como lo hizo el de Franco después de 1945 e incluso tener una desembocadura como la de éste" ${ }^{m 9}$. Altamente probable es también que si Franco hubiese entrado en guerra su régimen se habría acabado como el de Mussolini.

Con respecto al nivel de institucionalización, Tusell afirma que "el peso de las instituciones en el régimen fascista italiano fue siempre mayor que el la España de Franco"40. Afirmación que se puede sin duda compartir, pero que añade muy poco a la comprensión de los dos regímenes. Lo que no se puede compartir es el ejemplo con que la fundamenta. Escribe Tusell que la caída del régimen de Mussolini "se produjo como consecuencia de una reunión del Gran Consiglio fascista..., mientras que ni por un momento puede resultar imaginable que el Consejo del Reino o el Consejo Nacional pudieran plantear a Franco la eventualidad de una dimisión ${ }^{141}$. La verdad es que Musolini cayó el 25 de julio de 1943 porque estaba perdiendo la guerra y no "como consecuencia de una reunión del Gran Consiglio". Y si Franco hubiera entrado en guerra y hubiera sido derrotado es muy probable que alguna institución habría decretado su cese. Alfonso XIII se marchó de Madrid después del triunfo de los partidos republicanos en las elecciones municipales. Umberto I, el rey de mayo, se fue después del Referendum institucional que decretó el fin de la

\footnotetext{
${ }^{38}$ J. Tusell, La dictadura de Franco, Madrid, Alianza, 1988, p. 319.

${ }^{39}$ Idem, pp. 310-311.

${ }^{40}$ Idem, p. 322.

${ }^{41}$ Idem, p. 323.
} 
monarquía en Italia. Si hay reglas y costumbres distintas, o un diferente peso de las instituciones en los dos países, es algo que se refiere a la historia no a los regímenes. Mucho menos tiene que ver "con el grado de totalitarismo del fascismo italiano y del franquismo, un punto en el que reside la esencia de la diferencia entre ambos regimenes", como escribe Tusell ${ }^{42}$.

El problema de la movilización extensiva de la población es otro aspecto sobre el cual se ha discutido bastante. Tusell considera similar el control de la prensa y la creación de organismos para la socialización de la política en la vida cotidiana o entre la juventud, y como rasgo distinto indica el hecho de que la movilización política en el franquismo no fue ni habitual ni total ${ }^{43}$. Pero tenemos que preguntarnos sobre las funciones y las finalidades de la movilización o de la desmovilización en los diferentes marcos nacionales. Mussolini llegó al poder en una Italia en la cual, en las elecciones de 1919 los socialistas habían conseguido alrededor del 35\% de los votos, en la que desde 1921 actuaba un fuerte Partido comunista que había creado una situación preinsurreccional con la ocupación de las fábricas en el Norte en el bienio rojo (1919-20) y en la cual socialistas, comunistas, demócratas y católicos demócratas seguían existiendo. En el sentido de que callaban por la coerción de los aparatos del Estado y de las milicias fascistas, pero estaban vivos. A Mussolini le hizo falta mantener la tensión para que la oposición quedara aislada y no se reorganizase. Y lo consiguió también por medio de la movilización. Por contra Franco no tuvo esta necesidad, puesto que gran parte de sus enemigos habían sido eliminados físicamente: en la guerra civil, con el exilio y con la cárcel.

Mussolini se metió en tres guerras: la civil española, la de Africa para la conquista del Imperio y la segunda guerra mundial. Y sin la moral y el sustento de una fuerte movilización no hay quien se vaya a la guerra. Por contra Franco, División Azul aparte, permaneció fuera del conflicto mundial. Entonces, ¿para qué movilizar constantemente las multitudes?.

Otra comparación se refiere al distinto papel del partido único en los dos contextos. A este respecto Tusell destaca, a partir de Emilio Gentile ${ }^{44}$, el papel central del PNF en Italia y su incorporación en el Estado ${ }^{45}$. Él encuentra un rasgo similar en la dualidad entre Mussolini y el PNF por un lado, y entre Franco y la Falange por el otro. Afirma que en España el partido tuvo un papel menor que explica con sus orígenes: la unificación desde arriba. Concluye escribendo que "el pluralismo fascista era reducido en el seno del partido; el pluralismo del franquismo era consubstancial y al margen del partido" ${ }^{146}$. En general, por lo que se refiere al papel del partido, habría que preguntarse si las diferencias surgen de la distinta

\footnotetext{
${ }^{42}$ Ibidem.

${ }^{43}$ Idem, p. 329.

${ }^{44}$ E. Gentile, "Il problema del partito nel fascismo italiano", en Storia contemporanea, 1984, pp. 347-370. Pero del mismo autor véase también el sucesivo Storia del partito fascista, 1919-1922. Movimento e milizia, Roma-Bari, Laterza, 1989.

${ }^{45} \mathrm{~J}$. Tusell, op. cit., p. 332.

${ }^{46}$ Idem, p. 334.
} 
naturaleza de los regímenes, o si es el diferente papel que la "forma partido" juega en la historia de los dos países la que determina las diferencias. Es más: desde una perspectiva menos angosta, como la que hoy en día empieza a ser posible, habría que preguntarse si PFN y Falange-Movimiento, tienen algo que ver con la organización, la colocación entre sociedad civil y Estado, etc. de los partidos del post fascismo y del post franquismo.

No convencen, en fin, dos afirmaciones de Tusell con respecto al distinto papel de la oposición católica y en el plano de la política económica. La primera se refiere al hecho de que mientras en España no hay oposición católica hasta el Concilio, en Italia hubo una minoría en el exilio (Sturzo, Ferrari) que hizo oir su voz y algunos marginalizados (De Gasperi, Gronchi) que tuvieron su papel ${ }^{47}$. Pero mirando hacia atrás, la cuestión se plantea de otra forma. La experiencia del PPI de Sturzo lleva consigo la democratización de un sector católico, partido y papel en nada equivalente a la CEDA. También habría que acordarse que de los líderes políticos católicos españoles que habrían podido oponerse, José Antonio Aguirre y Manuel de Irujo, que por ser nacionalistas vascos no dejan de pertenecer a la categoría de los católicos demócratas, lo hicieron desde el exilio, mientras que a otro, Manuel Carrasco i Formiguer, no se le dejó tiempo.

La segunda afirmación se refiere a la política económica de Mussolini, del cual Tusell cita la frase "No puede tolerarse el predominio de la burguesía conservadora" para decir que la mentalidad cuartelera dominante en el franquismo nunca hubiera subscrito esta afirmación musoliniana ${ }^{48}$. Hecho cierto, pero que olvida las diferencias entre las declaraciones y los hechos, hasta el punto que podría decirse que incluso la burguesía conservadora italiana habría podido subscribir la frase de Mussolini a cambio de los beneficios que indudablemente tuvo durante el régimen (puesto que se fascistizó, apoyó al régimen y se aprovechó de él de una forma considerable).

Después del largo recorrido, que por ser en algunos aspectos criticable, no deja de ser rico y lleno de sugerencias, Tusell escribe que: "La conclusión que del libro resulta es -me parece- un desmentido a la supuesta peculiaridad de España en la historia contemporánea". Y más adelante añade que "el mito de la peculiaridad nacional queda pulverizado desde el momento que comparamos seriamente lo acontecido en España en 1939-1945 con otros fenómenos dictatoriales en el mismo período cronológico, en especial si se trata de contextos sociales y culturales relativamente semejantes" ${ }^{49}$. Si Tusell tiene razón, como creo y no dejo de repetir con relación a los aspectos de la historia española que he investigado, la perspectiva desde la cual tiene sentido una comparación histórica entre los dos regímenes es, entonces, la que arranca desde la historia de los dos países y que comparte Tusell cuando afirma "En el fondo los interrogantes que a los gobernantes de esas dictaduras se les planteaban eran los mismos y las respuestas, siendo matizadamente

\footnotetext{
${ }^{47}$ Idem, p. 337.

${ }^{48}$ Idem, p. 349.

${ }^{49}$ Idem, pp. 357-358.
} 
distintas, se enmarcaban dentro de un ámbito de similitud" ${ }^{50}$.

4. A la hora de sacar algunas conclusiones de carácter general, merece la pena formular las sugerencias metodológicas siguientes que, a lo mejor, pueden ayudar en la tarea de llevar a cabo una correcta comparación entre el régimen de Franco y el de Mussolini.

Tiempos y lugares. Nos encontramos en el período entre las dos guerras mundiales, frente a la crisis del Estado liberal y a sociedades en las cuales las masas han aparecido. Quizá merezca la pena parafrasear el refrán árabe empleado por Marc Bloch para decir que los regímenes políticos se parecen más a sus tiempos que a sus padres $^{51}$. Nos encontramos geográficamente en la Europa del Sur, mediterránea y católica.

Nos encontramos, en fin, frente a unos regímenes que, por una significativa temporada, están directamente vinculados. Además, el fascismo italiano es desde el principio un aliado, un modelo y una fuente de inspiración.

Hay motivaciones de sobra para decir que esa comparación, más que posible, resulta necesaria. ¿Hace falta repetir la conocida afirmación de Tocqueville, según el cual quien haya visto y estudiado sólo Francia no entenderá nunca nada de la Revolución Francesa?.

Propaganda e imágenes. Han existido posturas propagandísticamente incluyentes o excluyentes del franquismo de la categoría del fascismo que hoy no sirven para nada. Como también las autorrepresentaciones del propio régimen: filofascista hasta 1942-43, no fascista después. La proclamación de que "España es diferente" puede explicarse también como toma de distancia de los regímenes de Hitler y Mussolini. Pero propaganda y autorepresentaciones ocultan más de lo que dejan ver. Sirven para el estudio, hoy muy de moda, de la imagen, que indudablemente es historia, pero no toda la historia. A lo mejor es historia de las imágenes. A lo peor sólo un simulacro de historia.

Movimiento y régimen. La distinción empleada por Renzo De Felice con respecto del fascismo italiano, entre el programa del movimiento fascista y su cristalización/falsificación en el régimen, es útil bajo distintos aspectos. Por ejemplo para comprobar que la caracterización laica y anticlerical del fascismo-movimiento se pierde completamente, o casi, en los años treinta (después del Concordato y de la solución del conflicto entre el régimen y la Acción Católica de 1931). A esta altura la confesionalidad del régimen italiano (y la aportación católica al mismo), constituye una situación muy similar a la del franquismo a lo largo de su historia.

Regímenes y procesos históricos. Cuando se comparan los dos regímenes para establecer el grado de totalitarismo, o de fascismo, los que se pierden son los objetos, en el sentido antes precisado, de la comparación. Mientras lo que se compara es, en efecto, el estado (más totalitario, menos fascista) con una propriedad (totalitarismo,

\footnotetext{
${ }^{50}$ Idem, p. 359.

${ }^{51}$ M.Bloch, Apologia della storia o il mestiere di storico, Torino, Einaudi, 1969 (1949), p. 48.
} 
fascismo) construida en abstracto. Para recuperar los verdaderos objetos de la comparación habría que poner en el centro de la atención los regímenes en su relación con los procesos históricos. Sin esta valoración de conjunto las estructuras políticas flotan entre las nubes y la comparación es algo que se refiere a las formas de los sistemas políticos. ¿Hay quién no admita que sistemas políticos parcialmente diferentes pueden surgir para solucionar problemas parecidos?.

Lo comparable y lo no comparable. Ha existido en Italia un movimiento fascista (1919-22), un partido nacional fascista, un regimen fascista con fases diferentes: de consolidación (25-31), de consenso (32-38), de guerra (40-43), de República Social (43-45). Ha existido en España una corriente protofascista en los años veinte, un movimiento filofascista en los años de la República, un régimen en construcción en los años de la guerra civil, un franquismo-fascismo (39-42), un primer franquismo (años cuarenta), un franquismo de los años cinquenta, sesenta y setenta. ¿Por qué a menudo se olvida que la comparación tiene sentido, bajo no pocos aspectos, sólo por segmentos cronológicos homogéneos?.

Así como hace falta distinguir las intenciones y los hechos, las autorrepresentaciones y la realidad, los programas y las realizaciones, la ideología y los procesos históricos, hay que comparar los proyectos con los proyectos, los hechos con los hechos. Y desde programas diferentes pueden resultar procesos histórico similares.

Notarios e historiadores. Se han hecho elencos contundentes de las diferencias entre los dos regímenes: en el origen, en la forma de ascenso al poder, en el papel del partido único, en el nivel de movilización, en el grado de totalitarismo, etc. Incluso personales entre las diferentes actitudes de los dos dictadores. Pero la actitud notarial resulta meramente descriptiva. Quince diferencias no hacen una diversidad substancial, como la distinta colocación de las plantas entre ellas y las diferentes alturas de los arboles agrupados en dos grandes bloques no impide que sean bosques los dos.

Teólogos, médicos e historiadores. El raptus místico que sube al historiador hacia el cielo de la teología no es infrecuente. Ocurre todas las veces que se empeña en la búsqueda de la esencia o de las naturalezas de un determinado régimen. Esta actitud traiciona la idea de que se trata de una enfermedad que hace falta individuar. Pero ni el fascismo, ni el franquismo han sido enfermedades contraídas por un virus venido desde fuera, sino el producto (no necesario, pero de hecho, cierto) del propio cuerpo en su desarrollo. No se trata entonces de reseñar la sintomatología para individuar la enfermedad y establecer la terapia adecuada. Se trata de entender cómo ha sido posible y por qué. En otras palabras cómo se ha realizado el crecimiento y el desarrollo de este cuerpo. Esta actitud tiene además algo anacrónico. Pertenece a los años cincuenta, cuando a cierta diplomacia y a cierta política exterior le hacía falta legitimar a un posible interlocutor para justificar el rechazo de relaciones con otros. Se dió entonces la elucubración de una politología al servicio de una política. ¿No podría la historiografía de los noventa pasar de esta herencia?.

Todavía más peligroso, este afán hacia las esencias y las naturalezas resulta cuando se pone en el marco de una comparación. Porque, de esta forma, son las esencias y las naturalezas las que verdaderamente se comparan en un juego de espejismos donde la realidad de los procesos históricos no entra ni tan siquiera como 
pretexto. ¿Qué más da para la comprensión de un régimen en relación con otro el despliegue de adjetivación (incompleto, defectivo, imperfecto, tendencial, etc.) a propósito del totalitarismo, si éste no es más que un modelo abstracto? El castillo de la comparación está poblado por fantasmas. Ya llega la primera ola de los fantasmas de Clio.

Idealtipos y estereotipos. Muchas veces los historiadores emplean modelos idealtípicos elaborados por otras ciencias sociales por medio de un proceso de abstracción de conceptos que no tienen ni idea de la complejidad de los hechos históricos y de las investigaciones historiográficas.

Lo prueba abundantemente el hecho de que la evolución de la investigación historiográfica no afecta en nada la configuración de estos modelos que, establecidos una tantum (es decir: con un nivel de conocimiento determinado por la época de su elaboración), parecen quedarse incorruptibles dentro de una esfera de cristal.

Además habría por lo menos que averiguar si un modelo $\mathrm{X}$, elaborado fuera de la historiografía, tiene el mismo significado en otro contexto. Es el tema de la traducibilidad de los modelos. $O$ dicho de otra forma, del estatuto epistemológico de los modelos. La historiografía tiene dos opciones: elaborar sus propios modelos o verificar la validez epistemológica de los que adopta y emplea.

El proceso de construcción de los modelos tiene su trascendencia. Si se construye el de fascismo a partir del caso italiano, luego no queda otro remedio que aplicarlo a las otras realidades para comprobar identidades y diferencias. Mientras que si lo construimos a partir de los regímenes que en determinados países, en un tiempo determinado y similar, han jugado el mismo papel o un papel similar, el resultado del modelo será muy distinto del anterior.

En todo caso habría que evitar que los modelos funcionaran por libre, substituyendo a las realidades empíricas. En este caso, no infrecuente, el razonamiento historiográfico es llevado a cabo por medio de estereotipos. No otra cosa llegan a ser los modelos de fascismo, de totalitarismo, de autoritarismo en sus abstracciones. Constituyen la segunda ola de los fantasmas de Clio.

5. El estado de los estudios con anterioridad reseñados resulta demasiado deudor del debate sobre el fascismo y el totalitarismo propio los años cincuenta y sesenta. Es decir que parece todavía no adecuadamente en relación con los lugares del debate historiográfico actual. Y entre ellos un lugar indudablemente privilegiado ocupan el estudio de los procesos de nacionalización y de modernización.

Habrá además que prestar mayor atención sobre aspectos que la historiografía ha desarrolado hasta la fecha de una forma no homogénea en los dos países, como el de la continuidad o de la ruptura entre los regímenes de Mussolini y de Franco. lo que había antes y lo que ha venido después; o como el de la organización de los aparatos represivos del Estado (jueces, leyes de seguridad ciudadana y de orden público, cárceles, policía, etc.); o, en fin, como el de la formación y del papel de la burocracia frente a la anterior y a la que ha venido después.

La historia comparada favorece una inversión de tendencia frente al minimalismo historiográfico hoy tan de moda y puede facilitar la recuperación de los grandes 
temas, de las preguntas "fuertes", frente a la invasión de objetos pretextuosos y efímeros de la historiografía postmoderna. Es una razón más para afirmar que merece la pena seguir en este camino. 